\title{
Open Label for Treatment And Double Blind to Dose
}

National Cancer Institute

\section{Source}

National Cancer Institute. Open Label for Treatment And Double Blind to Dose. NCI

Thesaurus. Code C156592.

A study in which the therapeutic treatment is open label but the dosing information of the investig ational medicinal product (IMP) is double-blinded. 